\title{
FALLOPIAN TUBE LEIOMYOMA: A RARE CLINICAL ENTITY
}

Punyabrata Mohapatra ${ }^{1}$, Sahadev Sahoo ${ }^{2}$, Rabindra Nath Behera ${ }^{3}$

\section{HOW TO CITE THIS ARTICLE:}

Punyabrata Mohapatra, Sahadev Sahoo, Rabindra Nath Behera. "Fallopian Tube Leiomyoma: A Rare Clinical Entity". Journal of Evolution of Medical and Dental Sciences 2014; Vol. 3, Issue 66, December 01;

Page: 14418-14420, DOI: $10.14260 /$ jemds/2014/3933

INTRODUCTION: Leiomyomas arise from smooth muscle cells of uterus or vascular walls that supply the uterus. Very rarely the ovary, broad ligament and fallopian tubes can also be involved. Though the uterus and tubes are derived from Mullerian system and both contain smooth muscles, uterine myomas are very common whereas fallopian tube myomas are least frequently encountered. Most cases of fallopian tube leiomyomas are asymptomatic and chance-findings at surgical exposure for other reasons or found only at autopsy.

KEYWORDS: Fallopian tube, Leiomyoma

CASE REPORT: A 41- year Para 3 was admitted with colicky pain abdomen with vomiting and features of dehydration. Her cycles were 5-7 days /30 days with excessive flow accompanied with pain and dyspareunia since 7 months. Her L. M. P. was 7 days prior to admission. She was treated with antibiotics for PID in peripheral institutions during this period. All her deliveries were normal with uneventful post-partum period and she underwent minilap tubal ligation 11 years back. Her vitals were stable, abdominal examination revealed a tender distended lower abdomen. On pelvic examination a tender ill-defined mass attached to uterus with restricted mobility was felt in the left adnexa.

USG reported Left adnexal mass simulating Left Ovarian Cyst (Fig. 1).The uterus was normal in size with thin endometrium and the endometrial cavity was empty.

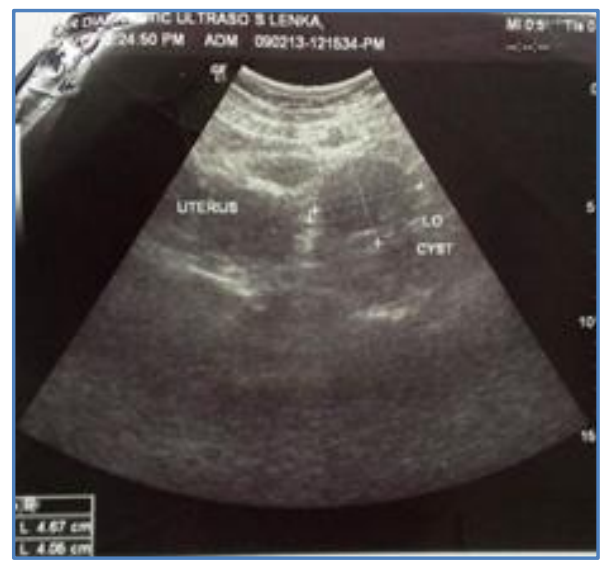

\section{Fig. 1: USG simulating an ovarian cyst}

The blood picture reveled $\mathrm{Hb}$ count 11 gram/dl, TLC 10, 200/cmm, $\beta$-hcg $6 \mathrm{ng} / \mathrm{ml}$, other tumour markers (CA 125, CEA, AFP, LDH) within normal limits.

With provisional diagnosis of Twisted Ovarian tumour (left) or degenerated subserous fibroid, we proceeded with the case. After counseling the family members for laparoscopy vs 


\section{CASE REPORT}

laparotomy, under G. A. laparoscopy was performed, which showed a mass in the left fallopian tube at the isthmic portion undergone torsion. The uterus, right tube and ovary were normal. After untwisting the mass LAVH with BSO was performed. The specimen clearly showed a left fallopian tube leiomyoma (Fig 2). Post- operative period was uneventful.

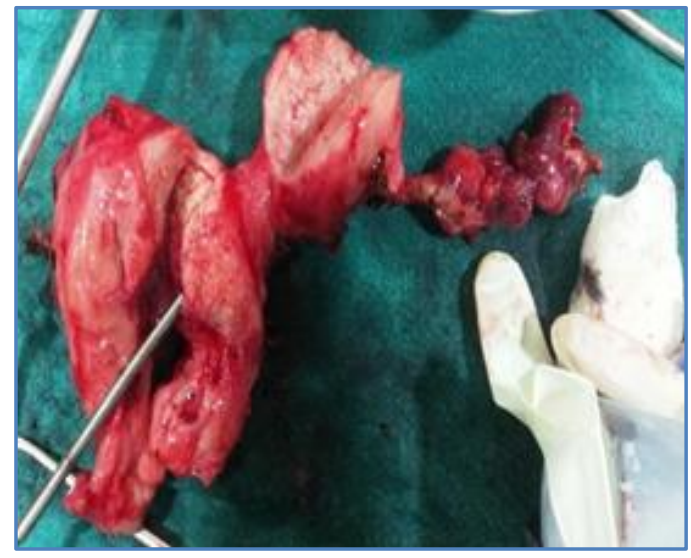

Fig. 2: Showing left tubal solid growth at its isthmic portion

The histopathology report came out to be LEFT FALLOPIAN TUBE ADENOLEIOMYOMA at its isthmic portion without any features of malignancy.

Discussion and review of Literature: Leiomyomas of fallopian tube are rare, typically co- incidental findings at autopsy or unrelated surgical procedures.[1] They are mostly single, small and unilateral but may be of variable size from microscopic to more than $15 \mathrm{~cm}$ large.[2] They may grow excessively and undergo torsion or degenerations. ${ }^{[3]}$ They are rarely diagnosed pre-operatively. Powerful USG could be helpful in diagnosing this condition, but laparoscopy can be used for definite diagnosis and management. ${ }^{4]}$ Neither CT nor laparoscopy sometimes could specify the tumour where final diagnosis is made by biopsy.[5] In 2004 for the first time a case could be successfully managed by laparoscopy.[6]

CONCLUSION: Asymptomatic fallopian tube leiomyoma being chance-findings are very rare and symptomatic fallopian tube leiomyoma as in this case are still rarer. This condition should be kept in mind as a differential diagnosis of any adnexal mass.

\section{REFERENCES:}

1. Misao R, Niwa K, Iwagaki S, Shimokawa K, Tamaya T. Gynecol obstet invest 2000; 49 (4) 27980.

2. yang $\mathrm{CC}$, wen $\mathrm{KC}$, chen $\mathrm{P}$, Wang $\mathrm{PH}$, primary leiomyoma of the fallopian tube; pre-operative ultrasound findings. J chin med Assoc 2007; 70: 80-83.

3. Tarek Bardawil, MD, MBA; Chief Editor: Richard Scott Lucidi, MD, FACOG. http://emedicine.medscape.com/article/275463-overview\#showall

4. Yang CC, Wen KC, Chen P, Wang PH. J Chin Med Assoc. 2007 Feb; 70 (2): 80-3.

5. Journal De Gynecologie Obstetrique Et Biologie De La Reproduction, Volume 37, Issue 8, December 2008, page 799-801. 


\section{CASE REPORT}

6. Wen Kc, Yang CC, Wang Ph. priamry fallopian tube leiomyoma managed by laparoscopy. J minim invasive gynecol 2005; 12: 193.

\section{AUTHORS:}

1. Punyabrata Mohapatra

2. Sahadev Sahoo

3. Rabindra Nath Behera

\section{PARTICULARS OF CONTRIBUTORS:}

1. P. G. Student, Department of Obstetrics and Gynaecology, Hi-Tech Medical College, Bhubaneswar, Odisha.

2. Assistant Professor, Department of Obstetrics and Gynaecology, Hi-Tech Medical College, Bhubaneswar, Odisha.

3. Professor, Department of Obstetrics and Gynaecology, Hi-Tech Medical College, Bhubaneswar, Odisha.

\section{NAME ADDRESS EMAIL ID OF THE CORRESPONDING AUTHOR:}

Dr. Sahadev Sahoo, Assistant Professor, Department of Obstetrics and Gynaecology, Hi-Tech Medical College, Bhubaneswar-751025, Odisha.

Email: drssahoo@outlook.com

Date of Submission: 20/11/2014.

Date of Peer Review: 21/11/2014.

Date of Acceptance: 27/11/2014.

Date of Publishing: 01/12/2014. 